\title{
Editorial for the Special Section on Rural and Remote ICT: Broadband Rural, Regional and National Impacts
}

Michael Lane

School of Management and Enterprise

University of Southern Queensland

Michael.Lane@usq.edu.au

\section{Catherine Middleton}

Ted Rodgers School of Management

Ryerson University

Catherine.Middleton@ryerson.ca

\section{Ruediger Zarnekow}

Institut für Technologie and Management

Technische Universitaet Berlin

ruediger.zarnekow@tu-berlin.de

\section{Khorshed Alam}

School of Commerce

University of Southern Queensland

Khorshed.Alam@usq.edu.au

The rapidly increasing digitalization of businesses and everyday life, combined with increased uptake of information and communication technology (ICT) enabled services such as Cloud Computing, Big Data Analytics and E-Commerce, puts high demand on local, national and global network infrastructures. High-speed, affordable and reliable broadband services have become a critical success factor for socio-economic transformation of any economy and society. Many broadband initiatives are underway at local and national levels, defining and rolling out future-proof broadband infrastructures needed for a digital age.

Despite significant progress in the development and deployment of the Internet in general and broadband services in particular, many open questions remain on technological, economic and societal levels. What network technologies and infrastructures are best suited for broadband access? How should investments in broadband infrastructures be financed? How can highspeed broadband services be rolled out in the most effective manner for rural and regional communities? And in which ways can society best benefit from broadband infrastructures and services?

With this overarching theme of Broadband Rural Regional and National Impacts in this special section of the Australasian Journal of Information Systems - Research on Rural and Remote ICT we want to foster discussion on broadband initiatives from different points of view (technological, economic and societal) and from different scopes (rural, regional and national).

Several important themes emerged from these four papers for this special section of the Australasian Journal of Information Systems. The first paper titled "The supply and use of broadband in rural Australia: An explanatory case study of the Western Downs Region” by Lane, Tiwari and Alam looks at the relationship between the supply and use of broadband and how this impacts on household satisfaction with broadband services in rural communities in the Western Downs region in Queensland and it also considers policy implications for delivering high speed broadband in Australian rural communities.

The second paper titled "Improving rural broadband deployment with synergistic effects between multiple fixed infrastructures" by Limbach, Kuebel and Zarnekow looks at a technoeconomic broadband deployment model as an efficient way to roll out broadband infrastructure by making use of existing physical infrastructure and cross-industry cooperation to deliver broadband infrastructure more efficiently for rural communities in Germany. 
The third paper titled "The Importance of Broadband for Socio-Economic Development: A Perspective from Rural Australia" by Freeman, Park, Middleton and Allen focuses on the poor broadband connectivity in rural communities which is exacerbating urban/rural disparities. It finds that current broadband policy frameworks need strategic adaptations to account for the socio-economic contexts of rural communities in order to narrow the current rural-urban digital divide in Australia.

Finally the fourth paper titled "The social surplus of broadband initiatives in compulsory education" by Parsons examines the critical role that high speed broadband infrastructure plays in delivery of compulsory education in New Zealand. Findings indicate that broadband can deliver a social surplus nationally justifying the investment in broadband infrastructure via the more effective provision of broadband based education.

These four research papers demonstrate the complexity and multi-disciplinarily of nature of broadband initiatives and the significance of their impact rural, regional and national levels.

We would like to end this editorial by acknowledging the reviewers and their contribution to this theme of Broadband Rural Regional and National Impacts in this special section. Their constructive feedback and comments to the prospective authors were invaluable and without their efforts this special section of AJIS would not be possible.

$\begin{array}{ll}\text { Lisa McDonald } & \text { Arifeen Mamun } \\ \text { Anup Shrestha } & \text { Sophia Imran } \\ \text { Marhaini Noor } & \text { Frank Elston } \\ \text { Ann Starasts } & \text { Reza Rajabiun }\end{array}$

We hope that you will find the papers in this special issue interesting and provide an impetus for future work in this important and under-researched area of Information Systems. We would also like to acknowledge the wonderful support that we received from the Editor-inChief, Associate Professor John Lamp.

Copyright: (C) 2016 Lane, Middleton, Zarnekow \& Alam. This is an open-access article distributed under the terms of the Creative Commons Attribution-NonCommercial 3.0 Australia License, which permits non-commercial use, distribution, and reproduction in any medium, provided the original author and AJIS are credited.

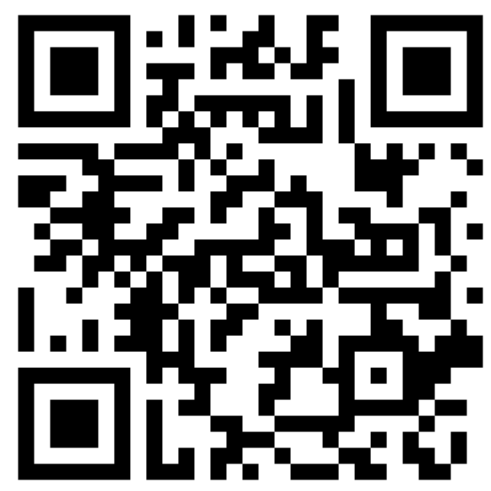

